\title{
Effect of Different Positions on Gastric Residual Volume of Preterm Neonates at Neonatal Intensive Care Unit
}

\author{
Nourhan Mohammed Anwar ${ }^{1}$, Nafisa Hassan Refaat ${ }^{2}$, Fathia Zaky Mohammed ${ }^{3}$ \& Hend Sayed Mohammed ${ }^{4}$ \\ 1. Clinical demonstrator of Pediatric Nursing, Faculty of Nursing, Assiut University, Egypt. \\ 2. Professor of Pediatrics, Faculty of Medicine, Assiut University, Egypt. \\ 3. Professor of Pediatric Nursing, Faculty of Nursing, Assiut University, Egypt. \\ 4. Lecturer of Pediatric Nursing, Faculty of Nursing, Assiut University, Egypt.
}

\begin{abstract}
Background: Nutritional management of premature neonates is regarded as a necessary and significant aspect of their care. Proper preterm neonatal positioning is necessary for physiological stability and nutritional status of neonates. So, this study aimed to evaluate the effect of different positions on gastric residual volume of preterm neonates in Neonatal Intensive Care Unit (NICU). Research design: A quasi-experimental research design was used. Sample. A Purposive sample of (60) preterm neonates who met the inclusion criteria at NICU of Assiut University Children Hospital. Two tools were utilized to collect the relevant data, Simple questionnaire sheet and Gastric residual volume record sheet. Results of the present study revealed that minimum gastric residual volume was prone position and maximum gastric residual volume was supine position. There was highly statistical significance difference between three different neonatal positions (right lateral, prone and supine) and amount of gastric residual volume. The study concluded that prone and right lateral positions had lower gastric residual volume than supine position in preterm neonates. So, the researcher recommended that periodical educational training programs for NICU nurses are required to keep nurse's knowledge up to date and to ensure that they had effective practice regarding proper position after feeding for preterm neonates.
\end{abstract}

\section{Keywords: Gastric residual volume, Position \& Preterm neonates.}

\section{Introduction}

Preterm neonates have greater rates of morbidity and mortality than full-term neonates due to their virtual physiologic and metabolic immaturity. However, due to the progresses in technology, preterm birth survival has increased significantly worldwide because of the reduction of neonatal morbidity and mortality (Huff et al, 2019).

Management of nutritional requirements of preterm neonates is difficult and needs higher calories for growth and development. Preterm neonates have higher nutrient requirements than term neonates because they have missed some or all of the third trimester of pregnancy, which is a period of nutrient accretion and rapid growth. Preterm neonates' whole growth, including their feeding mechanism is influenced by their immaturity (Gallardo et al., 2017).

Different methods of feeding premature neonates, these are enteral feeding including oral feeding such as breast feeding, bottle-feeding; gastric feeding in which milk is given directly in the stomach through nasogastric feeding (Gavage feeding); gastrostomy feeding; and transpyloric feeding (Samour \& King's., 2020).

Premature neonates often face various complications including respiratory, gastrointestinal and risk for nutritional problems (Feeding intolerance) because of weak sucking ability, unproductive swallowing, breathing problems, and immature organs, especially in the gastrointestinal system (Quinn et al., 2016). Feeding intolerance is frequent among preterm neonates. Feeding intolerance is characterized by difficulty in ingestion or digestion of the milk, resulting in a change in the enteral feeding plan due to clinical symptoms (Khashana \& Moussa., 2016).

In acute and critical care, gastric residual volume (GRV) measurements are regularly used to examine the quantity of stomach contents and to estimate premature tolerance or intolerance to enteral feeding (Khatony \& Batol., 2019). Evaluation of gastric residuals (GRs) is utilized in the NICU to determine the amount of milk remaining in the stomach at a various time after feeding, and as an indicator of gastric emptying (GE) when compared to term neonates (Hung et al., 2014).

Providing enteral feeding to preterm neonates is difficult because of immaturity of the digestive tract. One of the basic principles of the neonatal care is neonatal positioning, which is essential and noninvasive nursing intervention (Madlinger et al., 2014). Nutrition maintenance is one of the main methods to save premature neonates. 
In this regard, proper positioning is one of the key processes that is done by nurses. NICU nurses should place the preterm neonates in the most appropriate position based on their conditions (King \& Norton, 2017).

Preterm neonates' stomach residuals are affected by their appropriate position after feeding. Premature neonates are positioned in prone position should be under cardiopulmonary and arterial $\mathrm{O}_{2}$ saturation monitoring. Prone position with head of bed elevated 30 degrees enhances the oxygenation and respiratory control, energy expenditure and decreases gastric reflux. Right lateral position is preferred since it is associated with less GRs and quicker GE The supine position is linked to higher GRs and Gastroesophageal Reflux (GER) than any other nursing positions (Kaur \& Saini 2018).

Nurses caring for preterm neonates receiving enteral feeding face several challenges. Expertise and extreme care are crucial parts of delivering safe and effective nursing care to improve the quality of nursing care provided for them in order to increase the survival rate of these preterm neonates and lower morbidity and mortality rates (Rocha et al., 2018)

\section{Significance of the study}

Nurses need to be better educated about appropriate position of preterm neonates after feeding. The basic skills of changing position after feeding are simple to learn to healthcare providers and they can be utilized for lowering the amount of stomach residuals and many of problems that might arise in preterm neonates (Hussein, 2012). The present study was done to determine the effect of different positions on gastric residual volume of preterm neonates at NICU.

Aim of the Study:-

The present study was aimed to:

Evaluate the effect of different positions on gastric residual volume of preterm neonates at NICU

\section{Research hypothesis}

Preterm neonates who placed in different positions after feeding are expected to show lower gastric residual volume than control group.

\section{Subjects and Method}

A- Research design: A quasi-experimental research design was used.

B- Setting: The research was done at NICU of Assiut University Children Hospital.

C-Subjects:A purposive sample of (60) preterm neonates who meet the inclusion criteria.

They were randomly assigned into two groups:

a. Study group: (30) preterm neonates who were received intervention of positioning.

b. Control group: (30) preterm neonates who were received routine care only.
Inclusion criteria of Preterm neonates included:-

1. Preterm neonates fed using a nasogastric tube.

2. Gestational age ranged from $28-36$ weeks. Mean Apgar score at birth higher than 6 score at the $5^{\text {th }}$ minute.

3. Birth weight of $800 \mathrm{~g}$ and more.

4. Stable physiological status (heart rate, respiratory rate and Oxygen saturation).

5. Preterm neonates who were not connected on mechanical ventilation.

Tools of data collection:

Two tools were utilized to gather the relevant data:-

Tool (1): Simple questionnaire sheet:

It was established by the researchers to gather the required information and it included four parts:-

Part one: Preterm neonate characteristics such as (name, age, gestational age, gender, and weight)

Part two: personal characteristics of studied mothers' neonates such as (name, age, education, occupation, and residence)

Part three: Medical data of preterm neonates such as (type of delivery, Apgar score, diagnosis, and length of hospital stay).

Part four: Preterm neonate mother's medical data such as (diabetes, heart diseases, kidney diseases, hypertension, previous abortion, and previous C.S). Tool (2): Gastric residual volume record sheet:

It was adapted from Hussein, 2012 which was utilized to measure quantity of GRV left in stomach before giving formula feeding. It included 5 items which are time, amount of formula given, color, position of infant after feeding, and amount of gastric residual volume.

- Data collection: A formal permission was obtained from the director of the NICU in Assiut University Children Hospital to collect the required data for this research.

- A pilot study: was done on $10 \%$ (6) of preterm neonates to test the clarity and applicability of the sheet and to estimate the time needed to fulfill each sheet and the necessary modification including measuring GRV after 2hours not after one hour after feeding was done and the final form was developed and these were excluded from the total sample of the study.

- Tool one was established by the researcher after reviewing significant literature and it was confirmed for its content validity index by five experts jury in both pediatric nursing and pediatrics fields where its value was 0.98 .

- Tool two was valid and reliable by Hussein (2012), its alpha cronbach test was $(\mathrm{r}=0.7, \mathrm{p}<0,001)$.

- Important medical history was collected from the neonate's medical record and their mothers. 


\section{Field of the work:}

This research was carried out through six months period from the beginning of June (2020) to the end of November (2020). The researcher collected data in two days per week from 8 a.m. to 2 p.m., then the researcher apply intervention for 4 preterm neonates along the two days. The time needed for taking sociodemographic and medical data of preterm neonate from preterm neonate sheet was about 10 minutes.

Assessment of gastric residual volume was done before each feeding at $10 \mathrm{am}, 12 \mathrm{pm}$ and $2 \mathrm{pm}$ by using tool (2) gastric residual volume record sheet and it took 5 minutes.

\section{Intervention:}

- Gavage feeding was used using a well-placed nasogastric tube. During the gavage feeding, the gavage syringe was held $30 \mathrm{~cm}$ above the preterm newborn's head and the prescribed amount of milk was given in supine position with the head slightly up.

- Study group: First (at 8 am), the subjects were placed in right lateral position for two hours after feeding then measure GRV. Second (at $10 \mathrm{am}$ ), the subjects were placed in prone position for two hours after feeding then measure GRV. Third (at $12 \mathrm{pm}$ ), the subjects were placed in supine position for two hours after feeding then measure GRV.
- Control group: preterm neonates were received routine care only after feeding.

- The measured GRV of preterm neonates in three positions was compared by mean and standard deviation. If gastric residual volume was greater than $50 \%$ of previous feeding, it is an indicator of feeding intolerance (Parker, 2015)

\section{Ethical considerations}

Research proposal was accepted from ethical committee in the faculty of nursing. There were no risk for preterm neonates during application of the research. The researcher followed common ethical principles in clinical research. Confidentiality and privacy of the studied preterm neonates were asserted by the researcher. Parents were assured that the data of this research was used only for the purpose of research.

\section{Statistical analysis:}

Data entry and data analysis were done by using SPSS program (Statistical Package for Social Science) version 16. Data were presented as number, percentage, mean and standard deviation. Chi- square test and fisher exact test were used to compare qualitative data. For non-parametric quantitative data between the two groups, the Kruskal-Wallis Test was used. $\mathrm{P}$ value was considered statistically significant when $\mathrm{p}<0.05$.

\section{Results:}

Table (1): Percentage distribution of studied preterm neonates' characteristics and medical data

\begin{tabular}{|c|c|c|c|c|c|}
\hline & \multicolumn{2}{|c|}{ Study $(n=30)$} & \multicolumn{2}{|c|}{ Control $(n=30)$} & \multirow{2}{*}{ P. value } \\
\hline & No & $\%$ & No & $\%$ & \\
\hline \multicolumn{6}{|l|}{${ }^{a}$ Gender } \\
\hline Male & 15 & 50.0 & 18 & 60.0 & \multirow{2}{*}{0.603} \\
\hline Female & 15 & 50.0 & 12 & 40.0 & \\
\hline \multicolumn{6}{|l|}{${ }^{\pi}$ Birth Weight } \\
\hline $800<1000 \mathrm{~g}$ & 2 & 6.6 & 0 & 0.0 & \multirow{3}{*}{0.354} \\
\hline $1000<1500 \mathrm{~g}$ & 17 & 56.7 & 18 & 60.0 & \\
\hline$>1500 \mathrm{~g}$ & 11 & 36.7 & 12 & 40.0 & \\
\hline Mean \pm SD & \multicolumn{2}{|c|}{$1601 \pm 556.76$} & \multicolumn{2}{|c|}{$1599.03 \pm 535.73$} & 0.988 \\
\hline \multicolumn{6}{|l|}{${ }^{\pi}$ Gestational age } \\
\hline $28<31$ week & 11 & 36.7 & 11 & 36.7 & \multirow{3}{*}{1.000} \\
\hline $31<33$ week & 8 & 26.6 & 8 & 26.6 & \\
\hline 33-36 week & 11 & 36.7 & 11 & 36.7 & \\
\hline Mean \pm SD & \multicolumn{2}{|c|}{$32.43 \pm 2.49$} & \multicolumn{2}{|c|}{$32.47 \pm 2.43$} & 0.950 \\
\hline${ }^{\pi}$ Apgar Score at birth at $5{ }^{\mathrm{II}}$ minute & \multicolumn{2}{|c|}{$8.03+0.49$} & \multicolumn{2}{|c|}{$7.77+0.68$} & 0.086 \\
\hline \multicolumn{6}{|l|}{${ }^{\alpha}$ Diagnosis } \\
\hline RDS & 19 & 63.3 & 23 & 76.7 & \multirow{2}{*}{0.398} \\
\hline RDS \& LBW & 11 & 36.7 & 7 & 23.3 & \\
\hline \multicolumn{6}{|l|}{${ }^{\alpha}$ Type of feeding } \\
\hline Breast & 6 & 20.0 & 3 & 10.0 & \multirow{3}{*}{0.149} \\
\hline Formula & 13 & 43.3 & 13 & 43.3 & \\
\hline Both breast and formula & 11 & 36.7 & 14 & 46.7 & \\
\hline \multicolumn{6}{|l|}{${ }^{\pi}$ Amount of feeding } \\
\hline$<50 \mathrm{ml}$ & 30 & 100.0 & 30 & 100.0 & - \\
\hline \multicolumn{6}{|l|}{${ }^{\pi}$ Length of hospital stay per day } \\
\hline$>7$ days & 30 & 100.0 & 30 & 100.0 & - \\
\hline
\end{tabular}


Table (2): Comparison between study and control groups in the first day means of measured parameters

\begin{tabular}{|c|c|c|c|c|c|c|c|}
\hline & \multicolumn{2}{|c|}{$\operatorname{Study}(n=30)$} & \multirow{2}{*}{ Position } & \multicolumn{2}{|c|}{$\operatorname{Control}(n=30)$} & \multirow{2}{*}{ Position } & \multirow{2}{*}{ P. value } \\
\hline & No & $\%$ & & No & $\%$ & & \\
\hline \multicolumn{8}{|l|}{$\mathbf{1}^{\text {st }}$ day } \\
\hline \multicolumn{8}{|l|}{ 10AM } \\
\hline${ }^{\beta}$ Amount of formula given & \multirow{2}{*}{\multicolumn{2}{|c|}{$15.78 \pm 7.23$}} & \multirow{2}{*}{ Right } & \multirow{2}{*}{\multicolumn{2}{|c|}{$\frac{15.73 \pm 8.33}{2.51 \pm 1.89}$}} & \multirow{2}{*}{ Supine } & 0.744 \\
\hline${ }^{\beta}$ Amount of Gastric residual Volume & & & & & & & $<0.001 * *$ \\
\hline \multicolumn{8}{|l|}{${ }^{\alpha}$ Color } \\
\hline White & 16 & 53.3 & \multirow{4}{*}{ Right } & 12 & 40.0 & \multirow{4}{*}{ Supine } & \multirow{4}{*}{$<0.001 * *$} \\
\hline White \&brown & 0 & 0.0 & & 5 & 16.7 & & \\
\hline White \&yellow & 0 & 0.0 & & 13 & 43.3 & & \\
\hline Gastric juice & 14 & 46.7 & & 0 & 0.0 & & \\
\hline \multicolumn{8}{|l|}{ 12MD } \\
\hline Amount of formula given & \multicolumn{2}{|c|}{$16.48 \pm 7.25$} & \multirow{2}{*}{ Prone } & \multirow{2}{*}{\multicolumn{2}{|c|}{$\begin{array}{l}15.93 \pm 8.2 \\
2.91 \pm 1.59\end{array}$}} & \multirow{2}{*}{ Supine } & 0.588 \\
\hline Amount of Gastric residual Volume & 0.5 & $=0.47$ & & & & & $<0.001 * *$ \\
\hline \multicolumn{8}{|l|}{ Color } \\
\hline White & 12 & 40.0 & \multirow{4}{*}{ Prone } & 13 & 43.3 & \multirow{4}{*}{ Supine } & \multirow{4}{*}{$<0.001 * *$} \\
\hline White \&brown & 0 & 0.0 & & 15 & 50.0 & & \\
\hline White \&yellow & 0 & 0.0 & & 2 & 6.7 & & \\
\hline Gastric juice & 18 & 60.0 & & 0 & 0.0 & & \\
\hline \multicolumn{8}{|l|}{ 2PM } \\
\hline Amount of formula given & \multirow{2}{*}{\multicolumn{2}{|c|}{$\frac{16.95 \pm 7.16}{208+0.89}$}} & \multirow{2}{*}{ Supine } & \multirow{2}{*}{\multicolumn{2}{|c|}{$\begin{array}{c}16.1 \pm 8.1 \\
3.61 \pm 1.51 \\
\end{array}$}} & \multirow{2}{*}{ Supine } & 0.467 \\
\hline Amount of Gastric residual volume & & & & & & & $<0.001 * *$ \\
\hline \multicolumn{8}{|l|}{ Color } \\
\hline White & 19 & 63.3 & \multirow{5}{*}{ Supine } & 14 & 46.7 & & \\
\hline White \&brown & 8 & 26.7 & & 13 & 43.3 & & 年 $001 *$ \\
\hline White \&red & 0 & 0.0 & & 2 & 6.7 & Supine & $<0.001 \cdots$ \\
\hline White \&yellow & 3 & 10.0 & & 1 & 3.3 & & \\
\hline Gastric juice & 0 & 0.0 & & 0 & 0.0 & & \\
\hline
\end{tabular}

Table (3): Comparison between the mean measurements change among both study and control groups

\begin{tabular}{|c|c|c|c|c|c|c|}
\hline \multirow{3}{*}{ Mean measurements change } & \multicolumn{3}{|c|}{$\mathbf{1}^{\text {st }}$ day } & \multicolumn{3}{|c|}{$2^{\text {nd }}$ day } \\
\hline & $\begin{array}{l}\text { Study } \\
(n=30)\end{array}$ & $\begin{array}{c}\text { Control } \\
(\mathbf{n}=\mathbf{3 0})\end{array}$ & \multirow[t]{2}{*}{ P. value } & $\begin{array}{c}\text { Study } \\
(n=30)\end{array}$ & $\begin{array}{c}\text { Control } \\
(n=30)\end{array}$ & \multirow[t]{2}{*}{ P. value } \\
\hline & Mean \pm SD & Mean \pm SD & & Mean \pm SD & Mean \pm SD & \\
\hline \multicolumn{7}{|l|}{ 10AM } \\
\hline Amount of Formula given & $15.78 \pm 7.23$ & $15.73 \pm 8.33$ & 0.744 & $20.75 \pm 7.6$ & $18.87 \pm 7.37$ & 0.339 \\
\hline Amount of Gastric residual Volume & $0.81 \pm 0.69$ & $2.51 \pm 1.89$ & $<0.001 * *$ & $0.75 \pm 0.43$ & $2.12 \pm 0.89$ & $<0.001 * *$ \\
\hline \multicolumn{7}{|l|}{ 12MD } \\
\hline Amount of Formula given & $16.48 \pm 7.25$ & $15.93 \pm 8.2$ & 0.588 & $21.02 \pm 7.65$ & $18.97 \pm 7.3$ & 0.313 \\
\hline Amount of Gastric residual Volume & $0.57 \pm 0.47$ & $2.91 \pm 1.59$ & $<0.001 * *$ & $0.57 \pm 0.27$ & $3.1 \pm 0.81$ & $<0.001 * *$ \\
\hline \multicolumn{7}{|l|}{ 2PM } \\
\hline Amount of Formula given & $16.95 \pm 7.16$ & $16.1 \pm 8.1$ & 0.467 & $21.38 \pm 7.74$ & $19.1 \pm 7.22$ & 0.247 \\
\hline $\begin{array}{l}\text { Amount of Gastric residual } \\
\text { Volume }\end{array}$ & $2.08 \pm 0.89$ & $3.61 \pm 1.51$ & $<0.001 * *$ & $2.3 \pm 0.64$ & $3.99 \pm 1.04$ & $<0.001 * *$ \\
\hline
\end{tabular}

Kruskal-Wallis Test for non-parametric quantitative data between the three positions

*Significant level at $P$ value $<0.05$,

**Significant level at $P$ value $<0.01$ 
Table (4): Correlation Co-efficient between three different positions for study group \& Control group related to gastric residual volume with their Personal characteristics

\begin{tabular}{|c|c|c|c|c|c|c|}
\hline \multirow{3}{*}{ Correlation } & \multicolumn{6}{|c|}{ Gastric residual volume } \\
\hline & \multicolumn{3}{|c|}{ Study } & \multicolumn{3}{|c|}{ Control } \\
\hline & $\begin{array}{c}\text { 10am } \\
\text { (Right) }\end{array}$ & $\begin{array}{c}12 p m \\
\text { (Prone) }\end{array}$ & $\begin{array}{c}2 \mathrm{pm} \\
\text { (Supine) }\end{array}$ & $\begin{array}{c}\text { 10am } \\
\text { (supine) }\end{array}$ & $\begin{array}{c}\text { 12pm } \\
\text { (supine) }\end{array}$ & $\begin{array}{c}2 \mathrm{pm} \\
\text { (supine) }\end{array}$ \\
\hline Gender & $0.041 *$ & $0.037 *$ & 0.05 & 0.071 & $0.016 *$ & $0.047 *$ \\
\hline Birth Wight & -.202 & -.447 & -0.225 & -0.265 & -0.248 & -0.243 \\
\hline Gestational age & -0.34 & -.445 & -0.222 & -0.326 & -.374 & -.372 \\
\hline Apgar Score at birth & -0.27 & -0.172 & -0.35 & -0.109 & -0.289 & -0.438 \\
\hline Amount of feeding & 0.311 & 0.374 & 0.272 & 0.305 & .334 & .213 \\
\hline Length of Stay at hospital & 0.471 & 0.251 & 0.298 & 0.342 & 0.394 & 0.191 \\
\hline
\end{tabular}

*Statistically Significant Correlation at P. value $<0.05$

**Statistically Significant Correlation at P. value $<0.01$

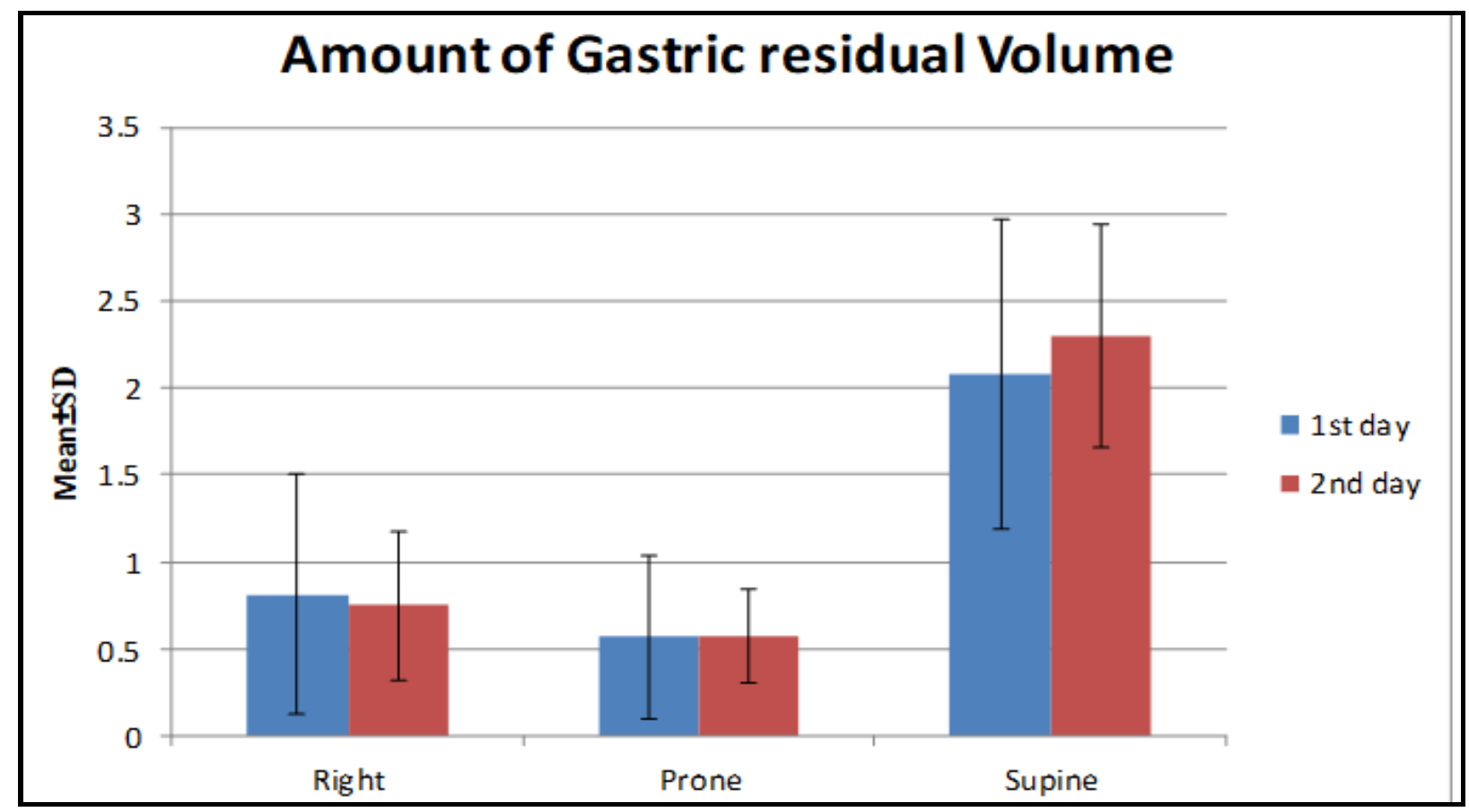

Figure (1): Comparison between three different Positions for study group related to gastric residual volume

Table (1): Shows studied preterm neonate's characteristics and medical data, it was found that, half $(50.0 \%)$ was male compared to less than two thirds $(60.0 \%)$ in control group. Preterm neonates' birth weight was between $1000<1500 \mathrm{gm}$ respectively in study and control group. Also Preterm neonates' gestational age was between $28<31$ week in study group while was between 33-36 week in control group. It was observed that Mean Apgar score at birth at $5^{\text {th }}$ minutes was $8.03+0.49$ in study group while $7.77+0.68$ in control group. Finding revealed that less than two thirds $(63.3 \%)$ of preterm neonates had RDS compared to more than two thirds $(76.7 \%)$ in control group. Type of feeding was less than half $(43.3 \%)$ in study and control group were being feeding formula milk. Apparently from the same table all studied preterm neonates had less than $50 \mathrm{ml}$ amount of formula. Concerning length of stay at hospital all studied preterm neonates had been hospitalized for more than 7days.

Table (2): Represents Comparison between Study and control groups in the first and second day means of measured parameters. It was found that at first day there was highly statistically significant difference $(<\mathbf{0 . 0 0 1} * *, \quad<\mathbf{0 . 0 0 1} * *, \quad<\mathbf{0 . 0 0 1} * *)$ between three different neonatal positions (right lateral, prone and supine) and amount of gastric residual volume. Prone position was the best position after feeding for preterm neonates in this study. 
Table (3): It was observed that there was highly statistically significant change $(<\mathbf{0 . 0 0 1} * *)$ between study and control groups related to amount of formula given and gastric residual volume in the first day and second day.

Table (4): There is negative non-significant correlation between (birth weight, gestational age, Apgar score at birth) and GRV. There is positive nonsignificant correlation between length of stay at hospital and GRV.

Figure (1): Demonstrates the comparison between three different positions for study group related to gastric volume, it was found that the best position for reducing GRV was prone position with mean $\pm \mathrm{SD}$ $(0.57 \pm 0.27)$ followed by right lateral position with mean $\pm \mathrm{SD}(0.75 \pm 0.43)$ and supine position with mean $\pm \mathrm{SD}(2.3 \pm 0.64)$.

\section{Discussion}

The position of neonate's body after feeding has also been identified as a significant factor influencing GE. Preterm neonates frequently suffer from GRs. GRs in preterm newborns are affected by position after enteral feeding. Nurses can use appropriate position after feeding as one of their strategies to help preterm neonates improve their feeding tolerance. The nutritional state of preterm newborns can be improved significantly with supportive nursing care related to nutrition. This care involves some basic attentions regarding the volume of feeding, type of formula, duration between successive feeds, GRV, and prevention of associated complications. Hussein, (2012), Ameri et al., (2018).

Results of the present study indicated that the mean value of gastric residuals in the prone position was significantly lower than that in supine position, this result may be due to that prone position reduces the number and severity of episodes of gastroesophageal reflux and amount of GRV after feeding. These results were consistent with Yayan et al. (2018) who found GRV was lower in right-lateral and prone positions and higher levels of gastric residuals in supine and left-lateral positions and also with Machado et al. (2020) who found that premature infants had a lower GRV and reduced risk for feeding intolerance during prone position compared to supine position, especially in the first 30 minutes after Enteral Nutrition administration while these results were in contrast with Jebreili et al. (2011) who reported the same effect of the right lateral position and prone position on the gastric residuals in preterm infants.

In the same line, the study found that gastric residuals volume were significantly lower in the right lateral position than those in the supine position, these results can be explained that right lateral position improves digestion stems after feeding for preterm newborns. Therefore, they suggested posing the preterm newborns in the right lateral position for the first two hours post-feeding and changing their position subsequently according to their behavior cues. These results were consistent with Sanger et al. (2013) they were investigated the effect of four body positions ( left lateral, right lateral, supine, and prone) on gastric residuals in preterm newborns and found that the frequency of gastric residuals was more in left lateral, compared to right lateral, prone, and supine positions. However, the difference was not significant in terms of supine position and also agree with Pandey et al. (2021) who stated that gastric empting was faster in right lateral position than left lateral position and contrast with Jebreili et al. (2011), they reported the same effect of the right lateral position and prone position on the gastric residual in preterm infants. Therefore, the utilization of both positions was recommended after gavage feeding.

The present study found that prone position had the lowest GRV compared with other positions. This results supported by Khatony \& Batol., (2019) who indicated that prone position was the lowest GRV and greatest potential for nutritional absorption. These were the same results reached by Moon (2011) who reported that prone position was associated with lesser gastric residual volume and less episodes of regurgitation. While this finding was dissimilar with Hawang et al. (2003) who measured GRV in different positions (prone, left-lateral, supine, rightlateral, full right-lateral, and full right-lateral recumbent). They stated that GRV was the lowest in right-lateral position $(p<0.05)$.

The current study findings revealed that there was no statistically significant difference between two groups in some of demographical variables like birth weight, gender, diagnosis, gestational age, Apgar score, and delivery method. This finding contradicts with that of Kaminski et al., (2014) who found that some of demographical variables like birth weight, gender, cause of hospitalization and delivery method had significant differences among the three groups, and presented that some variables such as gestational age, respiratory distress could be the interpreters of gastric retention.

Finding of the study showed that there was highly statistical significance change were found between study and control groups related to amount of formula given and gastric residual volume in the first day and second day. this finding was in agreement with chen et al (2013) who indicated that GRV after enteral feeding in prone position was significantly lower than supine positions at all measurement points and contradicts with that of khatony \& Batol., (2019) 
who found that there was no significant different between the three positions in term of gavage volume. Regarding correlation between gestational age, Apgar score at birth and GRV, there was a negative nonsignificant correlation between gestational age, Apgar score at birth and GRV. These findings go on line with the finding of Sangers et al., (2013) who found that there was a negative correlation between gestational age and incidence of gastric residuals.

There was a negative correlation between birth weight and GRV. This finding agreed with the finding of the study done by Li et al., (2014) who found that there was negative relation between birth weight and (GRV and FI).

As regard effect of the three positions (prone, right lateral and supine positions) on GRV, study showed the lowest to highest mean \pm SD of GRV respectively. This findings disagree with Mora et al (2017) who found that when positioned in right lateral, right anterior oblique, prone, and supine positions, preterm newborns had the lowest to the highest mean percentage of GRV, respectively.

Regarding length of NICU stay of the study sample, the current study found that the study group's stay was significantly shorter than control group's stay. This finding agreed with (Ahmed et al., 2019), who stated that implementing GRV protocol had a positive effect on critically ill patient outcomes as delivery of nutrients and calories and decreasing (length of hospital stay, and mortality).

\section{Conclusion}

Based on the results of the present study, it can be concluded that;

Prone and right lateral positions had lower gastric residual volume than supine position. Prone position reduces the number and severity of episodes of gastroesophageal reflux and amount of gastric residual volume after feeding and improving arterial oxygen saturation.

\section{Recommendations}

Based on the results of the present study the following recommendations can be suggested:

1- Periodical educational training programs for NICU nurses are required to keep nurse's knowledge up to date and to ensure that they had effective practice regarding proper position after feeding for preterm neonates.

2- NICU nurses should attend audiovisual conferences about practical procedures to increase their awareness with the recent approaches.

3- Future studies should be replicated and extended to include a large sample focusing on outcomes with different gestational ages with different positions in different settings.
4- Prone and right lateral positions should be incorporated as one of reducing gastric residuals modality in daily practice after feeding of preterm neonates.

5- NICU nurses should have a better knowledge of the interaction between position, and stomach residuals, which could aid nurses in providing efficient nutrition and performing the proper positioning of preterm infants after feeding.

\section{References:}

- Ahmed S, Mohammed M, \& Khalaf G., (2018): Effect of implementing gastric residual volume on critically ill patient outcomes, Journal of Medical Sciences, Vol (18), No (7), Pp:173-182.

- Ameri F, Rostami S, \& Aboli P., (2018): Effect of prone position on gastric residuals in preterm infants, Journal of Pharmaceutical Research International, Vol 22, No (2), Pp: 1-6.

- Chen S, Tzeng Y, Gau B, \& Chen J., (2013): Effects of prone and supine positioning on gastric residuals in preterm infants: a time series with cross-over study, International Journal Nursing Study, Vol (50), No (11),Pp: 1459-1467.

- Gallardo F, Contreras R, \& Keith V., (2017): Development of feeding skills in preterm infants, A critical literature review, Vol (19), No (2), Pp: 1982-2016.

- Huff K, Rose R, \& Engle W., (2019): Late preterm infants: morbidities, mortality, and management recommendations. Pediatric Clinical, Vol (66), No (2), Pp: 387-402.

- Hung F, Roberto C, \& Torrazza M., (2014): Gastric residual evaluation in preterm neonates: A Useful Monitoring Technique or a Hindrance?, Pediatrics \& Neonatology, Vol (55), No (5), Pp: 335-340.

- Hussein H., (2012): The Difference between right side and semi recumbent positions after feeding on gastric residual volume among infants, Journal of American science, Vol (8), No (1), Pp: 127-132.

- Hwang S, Ju H, Kim Y, Lee H \& Kim Y., (2003): Effects of body position and time after feeding on gastric residuals in LBW infants. Taehan Kanho Hakhoe Chi, Vol (33), No (4), Pp: 488-494.

- Jebraieli A., (2011): Effect of positioning on gastric residual of preterm infants. Medical journal of Tabrize University of medical sciences, Vol (23), No (2), Pp: 13-18

- Kaminski M, Clancy K, \& Steward D., (2014): Dilemmas surrounding interpretation of gastric residuals in the NICU setting. ICAN: Infant, Child, \& Adolescent Nutrition, Vol (6), No (5), Pp: 286294.

- Kaur V, \& Saini S., (2018): Comparison of three nursing positions for reducing gastric residuals in 
preterm neonates: A Randomized Crossover Trial, Indian pediatrics Journal, Vol (55), No (7), Pp: 568572.

- Khashana A, \& Moussa R., (2016): Incidence of feeding intolerance in preterm neonates in neonatal intensive care units, Journal of Clinical Neonatal, Vol (5), No (3), Pp: 230-232.

- Khatony A, \& Batol k., (2019): The effects of position on gastric residual volume of premature infants in NICU, Italian journal of pediatrics, Vol (45), No (6), Pp: 2-16.

- King C, \& Norton D., (2017): Does therapeutic positioning of preterm infants impact upon optimal health outcomes?, A literature review of Neonatal Nursing, Vol (23), No (5), Pp: 218-222.

- Li Y, Lin H, Torrazza R, \& Parker L. (2014). Gastric residual evaluation in preterm neonates: a useful monitoring technique or a hindrance, Pediatrics \& Neonatology, Vol (55), No (5) Pp: 335-340.

- Machado l. Rizzi P. \& Silva F. (2020): Administration of enteral nutrition in the prone position, gastric residual volume and other clinical outcomes in critically ill patients: a systematic review, Rev Bras Ter Intensiva Journal, Vol (32), No (1), pp: 133-142.

- Madlinger L, Reynoldds L, \& Zarem C., (2014): The effects of alternative positioning on preterm infants in the neonatal intensive care unit a randomized clinical trial ,Res Dev Disabil, Vol (35), No(2), Pp: 491-494.

- Moon R., (2011): Task Force on Sudden Infant Death Syndrome, SIDS and other sleep-related infant deaths: Expansion of recommendations for a safe infant sleeping environment, Pediatrics, Vol (12), No (8), Pp:1030-1039.

- Mora J, Punthmatharith B, \& Wattanasit P., (2017): Effect of positioning on gastric residual volume in preterm infants, Songklanagarind Journal of Nursing, Vol (37), No (4), Pp: 35-46.

- Quinn J. Munoz F. \& Gonik B. (2016): preterm birth: Case definition \&guidelines for data collection, analysis, and presentation of immunization safety data,Vaccine, Vol (34), No (49), Pp: 6047-6050.

- Rocha G. Soares P, \& Almeida D., (2018): Nutritional care for preterm infants, Canadian nutrition Journal, Vol (45), No (1), Pp: 1-12. Available at https:// doi.org / 10.1155/2018/7472964

- Samour A, \& kings F., (2020): Pediatric Nutrition in Clinical Care, Nutrition for Preterm Infants, 5th ed, United states of America :Ascend learning Co., PP: 121-141.
- Sangers H, de Jong P, Mulder S, \& Stigter G., (2013): Outcomes of gastric residuals whilst feeding preterm infants in various body positions. Journal of Neonatal Nursing, Vol (19), No (6): Pp: 337-341.

- Yayan E, Kucukoglu S, Dag Y, \& Karsavuran N., (2018): Does the post-feeding position affect gastric residue in preterm infants?, Breastfeeding Medicine, Vol (13), No (6), Pp: 438-443. 